\title{
PENGARUH PEMBERIAN JUS LABU SIAM TERHADAP PERUBAHAN TEKANAN DARAH PADA WANITA LANJUT USIA DENGAN HIPERTENSI DI WILAYAH KERJA PUSKESMAS NGORESAN
}

\section{The Effect of Chayote Juice Consumption on Blood Pressure Changes of Elderly Women with Hypertension in Work Area of Community Health Care of Ngoresan}

\author{
Rizky Suryaning Utami ${ }^{1)}$, Erindra Budi Cahyanto ${ }^{2)}$, Endang Listyaningsih S. ${ }^{3)}$ \\ ${ }^{*}$ Program Studi Kebidanan, Fakultas edokteran Universitas Sebelas Maret Surakarta \\ e-mail: liesgalleries@gmail.com
}

DOI: 10.13057/placentum.v\%vi\%i.22860

\begin{abstract}
ABSTRAK
Latar Belakang: Hipertensi merupakan masalah kesehatan masyarakat di dunia yang berkaitan erat dengan pola perilaku hidup masyarakat. Pengobatan hipertensi dapat dilakukan dengan terapi non farmakologis salah satunya dengan labu siam. Kandungan kalium dalam labu siam memiliki efek diuretik sehingga dapat menurunkan kadar garam dalam darah melalui ekskresi urin. Penelitian ini bertujuan untuk mengetahui pengaruh pemberian jus labu siam terhadap perubahan tekanan darah.

Metode: Penelitian ini menggunakan desain kuasi eksperimen dengan pretest and posttest with control group di wilayah kerja Puskesmas Ngoresan. Teknik sampling menggunakan purposive sampling. Besar sampel adalah 32 wanita lanjut usia yang memenuhi kriteria retriksi. Teknik pengumpulan data menggunakan lembar wawancara, observasi, dan sfigmomanometer. Teknik analisis data menggunakan Wilcoxon, uji $\mathrm{T}$ tidak berpasangan, dan Mann-Whitney.

Hasil: Rerata tekanan darah mengalami penurunan dari 153,13/93,75 $\mathrm{mmHg}$ menjadi $133,13 / 81,88 \mathrm{mmHg}$ setelah pemberian perlakuan. Hasil analisis data menunjukkan terdapat perbedaan yang signifikan pada tekanan darah sistolik $(\mathrm{p}=0,001<0,05)$ dan diastolik $(\mathrm{p}=0,000<0,05)$ kelompok yang diberikan jus labu siam.

Simpulan: Terdapat pengaruh pemberian jus labu siam terhadap perubahan tekanan darah pada wanita lanjut usia dengan hipertensi di wilayah kerja Puskesmas Ngoresan.
\end{abstract}

Kata Kunci : Hipertensi, Jus Labu siam, Lanjut usia 


\begin{abstract}
Background: Hypertension is a public health problem in the world that is closely related to the pattern of community life behavior. Treatment of hypertension can be done with nonpharmacological therapy one of them with chayote. Potassium content in chayote has a diuretic effect that can decrease the salt level in the blood through urinary excretion. This study aims to determine the effect of chayote juice consumption on blood pressure changes. Method: This study used quasi experimental design with pretest and posttest with control group in work area of community health care of Ngoresan. Technique sampling using purposive sampling. The number of sample is 32 elderly women who met the criteria of retreatment. Data collection techniques using interview sheets, observation, and sphygmomanometer. Data analysis techniques using Wilcoxon, unpaired T test, and MannWhitney.
\end{abstract}

Results: The mean of blood pressure decreased from 153,13 / 93,75 $\mathrm{mmHg}$ to 133,13 / $81,88 \mathrm{mmHg}$ after treatment. The results of the data analysis showed significant difference in group given chayote juice at systolic $(p=0.001<0.05)$ and diastolic blood pressure $(p$ $=0.000<0.05$ ).

Conclusion: There is an effect of chayote juice consumption on blood pressure changes of elderly women with hypertension in work area of community health care of Ngoresan.

Keywords: hypertension, chayote juice, elderly.

\section{PENDAHULUAN}

Hipertensi merupakan masalah kesehatan masyarakat yang berkaitan dengan pola perilaku hidup. Hipertensi masih menjadi masalah karena meningkatnya prevalensi hipertensi, masih banyak pasien hipertensi yang belum mendapatkan pengobatan maupun yang telah diobati namun tekanan darahnya belum mencapai target, dan adanya penyakit serta komplikasi berupa kerusakan organ target terutama pada jantung dan pembuluh darah yang memperburuk prognosis pasien hipertensi ${ }^{[1]}$.

Berdasarkan Buku Saku Kesehatan Jawa Tengah Triwulan 2 Tahun 2016, hipertensi merupakan urutan pertama dalam lima besar penyakit tidak menular ${ }^{[2]}$. Menurut data Riskesdas tahun 2013, prevalensi hipertensi di Indonesia sebesar 25,8\% dan di Jawa Tengah sebesar 26,4\% dimana umur 55 tahun keatas menjadi kelompok dengan prevalensi tinggi berdasarkan usia ${ }^{[3]}$. Data DKK Surakarta tahun 2015 menunjukkan jumlah lanjut usia dengan kasus hipertensi sebanyak 39.614 jiwa, sedangkan di Puskesmas Ngoresan tahun 2016 sebanyak 2.231 jiwa dan saat ini wanita lanjut usia yang mengalami hi- pertensi berjumlah 117 jiwa $^{[4]}$.

Terdapat dua jenis terapi hipertensi yaitu dengan farmakologis (medis) dan non farmakologis (herbal). Terapi non farmakologis adalah suatu pengobatan dengan tidak diberikan obat, yaitu dengan olahraga, mengurangi konsumsi rokok dan alkohol, dan diet sayuran atau buah, salah satunya dengan menggunakan labu siam. Labu siam merupakan sayuran yang tumbuh pada subtropis selain sebagai makanan juga digunakan sebagai obat. Labu siam banyak dikonsumsi masyarakat karena harganya cukup murah serta rasanya enak dan dingin ${ }^{[5]}$.

Kandungan kalium dalam labu siam diketahui memiliki efek diuretik sehingga dapat menurunkan kadar garam dalam darah melalui ekskresi urin ${ }^{[6]}$. Tujuan dari penelitian ini adalah untuk mengetahui pengaruh pemberian jus labu siam terhadap perubahan tekanan darah pada wanita lanjut usia dengan hipertensi di wilayah kerja Puskesmas Ngoresan.

\section{SUBJEK DAN METODE}

Penelitian ini dilakukan di wilayah kerja Puskesmas Ngoresan Surakarta pada bu- 
lan Maret 2017 - Juli 2017, menggunakan jenis penelitian kuasi eksperimen dengan pre test and post test with control group design. Populasi penelitian adalah semua wanita lanjut usia dengan hipertensi di wilayah kerja Puskesmas Ngoresan Surakarta yang memenuhi kriteria retriksi. Besar sampel sebanyak 32 responden dengan 16 subjek per kelompok dengan menggunakan teknik purposive sampling .

Variabel bebas dalam penelitian ini adalah konsumsi jus labu siam dan variabel terikat adalah perubahan tekanan darah. Instrumen yang digunakan adalah timbangan kue untuk mengukur berat labu siam. Pengolahan jus labu siam menggunakan pemarut dan penyaring. Pengukuran tekanan darah dengan sfigmomanometer. Informed consent untuk mengetahui kesediaan responden sebagai sampel penelitian. Lembar observasi untuk memantau konsumsi labu siam setiap hari. Alat tulis untuk mencatat hasil pengukuran pada lembar pengumpulan data. Kamera untuk mendokumentasikan pengambilan data.

Rerata awal dan akhir pada kedua kelom- pok diuji dengan Mann-Whitney, sedangkan untuk mengetahui pengaruh pemberian jus labu siam menggunakan uji Wilcoxon pada program SPSS 21.00 for Windows.

\section{HASIL}

\section{A. Analisis Univariat}

Karakteristik responden yang diteliti yaitu usia, riwayat keturunan hipertensi, dan pekerjaan. Tabel 1 menunjukkan bahwa sebagian besar usia responden adalah antara 60-74 tahun (lanjut usia), tidak memiliki riwayat keturunan hipertensi, dan tidak bekerja.

Tabel 2 menunjukkan bahwa rerata tekanan darah responden mengalami penurunan dari $153,13 / 93,75 \mathrm{mmHg}$ menjadi 133,13/81,88 mmHg setelah diberikan jus labu siam 100 gram sehari sekali selama 7 hari pada kelompok intervensi dan dari 148,75/91,88 $\mathrm{mmHg}$ menjadi $143,13 / 91,25 \mathrm{mmHg}$ pada kelompok kontrol.

Tabel 1. Karakteristik Responden

\begin{tabular}{lrr}
\hline \multicolumn{1}{c}{ Variabel } & Frekuensi (n) & Persentase (\%) \\
\hline Usia (tahun) & & \\
60-74 tahun (lanjut usia) & 28 & $87,5 \%$ \\
75-90 tahun (lanjut usia tua) & 4 & $12,5 \%$ \\
Riwayat keturunan hipertensi & & \\
Ya & 11 & $34,4 \%$ \\
Tidak & 21 & $65,6 \%$ \\
Pekerjaan & & \\
Wirausaha & 11 & $34,5 \%$ \\
Pekerja & 4 & $12,5 \%$ \\
Tidak bekerja & 17 & $53,1 \%$ \\
\hline
\end{tabular}

Tabel 2. Rerata Tekanan Darah Responden

\begin{tabular}{lrrr}
\hline \multicolumn{1}{c}{ Tekanan darah } & $\begin{array}{c}\text { Sebelum } \\
(\mathbf{m m H g})\end{array}$ & $\begin{array}{c}\text { Setelah } \\
(\mathbf{m m H g})\end{array}$ & $\begin{array}{c}\text { Selisih } \\
(\mathbf{m m H g})\end{array}$ \\
\hline Sistolik kelompok intervensi & 153,13 & 133,13 & 20 \\
Diastolik kelompok intervensi & 93,75 & 81,88 & 11,87 \\
Sistolik kelompok control & 148,75 & 143,13 & 5,62 \\
Diastolik kelompok control & 91,88 & 91,25 & 0,63 \\
\hline
\end{tabular}

\section{B. Analisis Bivariat}

Hasil uji analisis Mann-Whitney pada tabel 3 menunjukkan bahwa tidak terdapat perbedaan signifikan pada rerata tekanan darah sistolik dan diastolik antara kelompok intervensi dan kelompok kontrol se- 
belum diberikan perlakuan. Hasil rerata awal tekanan darah pada kedua kelompok hampir sama. Rerata tekanan darah sistolik dan diastolik antara kelompok intervensi dan kelompok kontrol setelah dibe- rikan perlakuan terdapat perbedaan signifikan. Hasil uji analisis Wilcoxon pada tabel 4 menunjukkan bahwa rerata tekanan darah pada kelompok yang diberikan jus labu siam terdapat perbedaan signifikan.

Tabel 3. Uji Beda Sebelum dan Setelah Diberikan Perlakuan

\begin{tabular}{|c|c|c|c|}
\hline Kelompok & n & $\begin{array}{c}\text { Tekanan darah } \\
\text { sistolik (p-Value) }\end{array}$ & $\begin{array}{c}\text { Tekanan darah } \\
\text { diastolik }(p \text {-Value })\end{array}$ \\
\hline \multicolumn{4}{|l|}{ Sebelum perlakuan } \\
\hline Intervensi & 16 & 0,064 & 0,123 \\
\hline Kontrol & 16 & & \\
\hline \multicolumn{4}{|l|}{ Setelah perlakuan } \\
\hline Intervensi & 16 & 0,0015 & 0,000 \\
\hline Kontrol & 16 & & \\
\hline \multicolumn{4}{|c|}{ Tabel 4. Uji Beda Kelompok Kontrol dan Kelompok Intervensi } \\
\hline Waktu perlakuan & $\mathbf{n}$ & $\begin{array}{c}\text { Tekanan darah } \\
\text { sistolik (p-Value) }\end{array}$ & $\begin{array}{c}\text { Tekanan darah } \\
\text { diastolik }(p \text {-Value })\end{array}$ \\
\hline \multicolumn{4}{|l|}{ Kelompok kontrol } \\
\hline Sebelum & 16 & 0,073 & 0,705 \\
\hline Setelah & 16 & & \\
\hline \multicolumn{4}{|l|}{ Kelompok Intervensi } \\
\hline Sebelum & 16 & 0,001 & 0,000 \\
\hline Setelah & 16 & & \\
\hline
\end{tabular}

\section{PEMBAHASAN}

\section{A. Analisis Univariat}

Usia responden paling banyak adalah 60 74 tahun $(87,5 \%)$. Hal ini terjadi karena semakin tua maka risiko mengalami hipertensi semakin tinggi karena elastisitas dinding pembuluh darah semakin menurun sehingga menyebabkan peningkatan nadi dan pembuluh darah. Sebagian besar hipertensi terjadi pada usia lebih dari 65 tahun. Hasil tersebut juga didukung oleh penelitian Andriansyah (2010) dengan yang menyatakan bahwa umur berpengaruh secara signifikan terhadap terjadinya hipertensi ${ }^{[7]}$. Seseorang yang berumur $\geq 45$ tahun memiliki risiko hipertensi sebesar 8,5 kali daripada responden yang berumur $\leq 45$ tahun. Perubahan tekanan darah yang fisiologis mungkin merupakan tanda penuaan yang normal ${ }^{[1][8]}$.

Sebagian besar responden tidak memiliki riwayat keturunan hipertensi $(65,6 \%)$. Hal ini sesuai dengan penelitian Yeni et al. (2010) yang menyatakan bahwa dari 58 responden yang memiliki riwa- yat hipertensi, 38 diantaranya tidak menderita hipertensi ${ }^{[9]}$. Menurut Kalangi et al. (2015) dan Setiadhi et al. (2016) tidak ada hubungan antara riwayat keluarga dengan tekanan darah ${ }^{[10][11]}$. Hasil ini berbeda dengan Purwanto (2012) bahwa adanya riwayat keluarga terhadap hipertensi dan penyakit jantung akan meningkatkan risiko terjadinya hipertensi karena keturunan dan ras merupakan salah satu faktor risiko hipertensi yang tidak dapat dimodifika$\mathrm{si}^{[1]}$.

Berdasarkan hasil wawancara, responden mengalami hipertensi karena pengaruh pola hidup yang sering mengonsumsi makanan tinggi garam (natrium). Natrium berfungsi sebagai nutrisi penting yang membantu saraf dan otot berfungsi dengan baik serta sebagai pengatur air dan keseimbangan cairan dalam tubuh. Asupan tinggi natrium menjadi tantangan berat bagi ginjal untuk mengeluarkan garam dalam jumlah besar. Salah satu sistem organ utama yang rentan terhadap efek buruk natrium yang berlebih dalam makanan 
adalah sistem kardiovaskular. Diet tinggi natrium menjadi faktor predisposisi tekanan darah tinggi ${ }^{[12]}$.

Responden penderita hipertensi sebagian besar tidak bekerja $(53,1 \%)$. Lanjut usia yang tidak bekerja rata-rata kurang aktivitas yang teratur dan efektif. Menurut hasil wawancara, baik responden yang bekerja maupun tidak bekerja tidak memiliki aktivitas fisik atau olahraga yang teratur. Hal ini sesuai dengan Larsen dan Matchkov (2016) bahwa latihan fisik dapat menjadi terapi non farmakologis potensial dalam pengobatan hipertensi dan penyakit kardiovaskular karena efeknya menguntungkan fungsi endotel melalui pengurangan stres oksidatif ${ }^{[13]}$.

Penting untuk memilih intensitas, durasi, frekuensi, dan jenis latihan yang tepat karena latihan yang tidak efektif menyebabkan disfungsi endotel dan cedera jantung terutama bagi atlet olahraga ekstrem dan lanjut usia. Hasil penelitian Mori et al. (2011) menyebutkan kelompok lanjut usia yang diberikan perlakuan aktivitas ringan dapat menurunkan hipertensi dan metabolisme glukosa serta lemak da$\operatorname{rah}^{[14]}$. Menurut Purwanto (2012) dan Pescatello et al. (2015), olahraga ringan dan aktivitas fisik lain setiap hari secara teratur selama kurang lebih 30 menit per hari yang dilakukan setiap hari atau 2-3 hari dalam seminggu dapat menurunkan tekanan darah dengan efektif sekitar 5-7 $\mathrm{mmHg}^{[1][15]}$.

\section{B. Analisis Bivariat}

Penurunan kadar estrogen dalam darah terjadi pada wanita menopause dan postmenopause menyebabkan perubahan pada sistem kardiovaskular yang berisiko untuk menderita penyakit arteri koroner dan hipertensi. Estrogen mempunyai efek vasodilatasi yang dapat menurunkan tekanan darah sistolik dan diastolik pada wanita dengan hipertensi. Sistem renin-angiotensin adalah salah satu sistem hormonal utama yang mengatur tekanan darah. Beberapa penelitian telah melaporkan perbedaan jenis kelamin dalam berbagai komponen renin-angiotensin pada tekanan darah.

Aktivitas renin plasma (ARP) pada populasi normotensi lebih tinggi pada pria daripada wanita tanpa memandang usia dan keturunan. Hormon seks wanita eksogen yang diberikan untuk kontrasepsi oral juga terbukti dapat merangsang produksi angiotensinogen, yang dapat menyebabkan peningkatan tekanan darah pada beberapa wanita. Penelitian lain menemukan bahwa ARP lebih tinggi pada pascamenopause daripada pada wanita pramenopause, meskipun ARP tetap lebih tinggi pada pria daripada wanita pada usia yang sama $^{[16][17]}$.

Hasil uji statistik menunjukkan bahwa terdapat pengaruh pemberian jus labu siam terhadap perubahan tekanan darah pada wanita lanjut usia dengan hipertensi di wilayah kerja Puskesmas Ngoresan. Kalium berguna untuk memelihara fungsi normal jantung dan sebagai regulator utama pembuluh darah. Kalium berfungsi sebagai vasodilator pembuluh darah yang dapat menurunkan tahanan perifer dan curah jantung sehingga tekanan darah menjadi normal, serta memperbaiki kepekaan terhadap natrium.

Kalium menurunkan kontraksi otot polos vaskular dengan mengubah potensi membran atau mengembalikan vasorelaksasi endotelium dan menimbulkankan efek seperti tiazid pada obat antihipertensi dengan cara menghambat reabsorbsi natrium klorida $^{[18][19]}$.

Hal ini sesuai dengan Samadian et al. (2016) bahwa meningkatkan konsumsi kalium dapat menurunkan tekanan darah pada orang dengan hipertensi serta tidak memiliki efek samping pada konsentrasi lemak darah, katekolamin, dan fungsi ginjal $^{[20]}$. Meta analisis yang mengevaluasi efek asupan kalium menyimpulkan bahwa konsumsi kalium $\geq 60 \mathrm{mmol}$ (2.350 gram) per hari dapat menurunkan rerata tekanan darah sistolik sebesar $4,4 \mathrm{mmHg}$ dan $2,5 \mathrm{mmHg}$ tekanan darah diastolik pada responden dengan hipertensi.

Penelitian Djaelani (2015) menunjukkan hasil sari buah labu siam berpengaruh me- 
nurunkan tekanan darah pada lanjut usia penderita hipertensi dengan rerata tekanan darah $170,71 / 96,82 \mathrm{mmHg}$ menjadi $148,94 / 87,52 \mathrm{mmHg}$ dan penurunan sebesar 21,57/9,3 $\mathrm{mmHg}$ setelah diberikan sari buah labu siam selama lima hari ${ }^{[21]}$. Hasil yang sama juga ditunjukkan Puspito (2014) pada 10 responden penderita hipertensi primer kelompok labu siam sebelum dan setelah mengonsumsi labu siam terdapat perbedaan rerata tekanan darah sebesar $16,2 / 8,8 \mathrm{mmHg}^{[22]}$.

\section{SIMPULAN}

Terdapat pengaruh pemberian jus labu siam terhadap perubahan tekanan darah pada wanita lanjut usia dengan hipertensi di wilayah kerja Puskesmas Ngoresan.

Perbedaan rerata tekanan darah sebelum pemberian perlakuan signifikan, menunjukkan rerata awal tekanan darah pada kedua kelompok hampir sama, sedangkan perbedaan rerata tekanan darah setelah pemberian perlakuan signifikan.

Perbedaan rerata tekanan darah kelompok intervensi sebelum dan setelah perlakuan signifikan pada tekanan darah sistolik dan diastolik.

\section{SARAN}

Responden dan masyarakat dengan hipertensi diharapkan dapat mengonsumsi jus labu siam 100 gram/hari terutama pada pukul 09.00-11.00 WIB untuk menurunkan tekanan darah.

Puskesmas Ngoresan dan Poslansia diharapkan dapat memberikan alternatif pengobatan non farmakologi pada lanjut usia dengan hipertensi di wilayahnya berupa jus labu siam untuk menurunkan tekanan darah.

Peneliti selanjutnya diharapkan dapat mengembangkan penelitian dengan menambahkan waktu lamanya pemberian perlakuan serta meneliti variabel lain yang dapat memengaruhi perubahan tekanan darah seperti keturunan dan ras, kebiasaan merokok, obesitas, dan penyakit penyerta seperti stroke, sehingga dapat mengurangi dampak yang ditimbulkan oleh hipertensi terutama pada lanjut usia.

\section{DAFTAR PUSTAKA}

1. Purwanto B (2012). Hipertensi (patogenesis, kerusakan, target organ, dan penatalaksanaan). Edisi ke 1. Surakarta: UNS Press, pp: 3-5, 8-25, 59-60.

2. Dinas Kesehatan Provinsi Jawa Tengah (2016). Buku saku kesehatan triwulan 2 tahun 2016. Semarang, pp: 78-79.

3. Kementerian Kesehatan RI (2014). Riskesdas 2013. pp: 145-146.

4. Dinas Kesehatan Kota Surakarta (2016). Profil kesehatan Kota Surakarta tahun 2015. Surakarta.

5. Juliyanto dalam Fitriyani NLC, Walanda DK, Rahman N (2012). Penentuan kadar kalium (K) dan kalsium (Ca) dalam labu siam (Sechium edule) serta pengaruh tempat tumbuhnya. J. Akad. Kim, 1 (4): 174-175.

6. Elisabeth dalam Jayani I (2016). Pemberian labu siam berimplikasi terhadap perubahan tekanan darah ibu hamil preeklampsi. Jurnal Care, 4 (2): 38 .

7. Andriansyah H (2010). Analisis hubungan faktor-faktor risiko hipertensi dengan kejadian hipertensi pada penduduk usia 20-65 tahun di Kecamatan Kaliwates Kabupaten Jember. Jember, Universitas Jember. Skripsi.

8. Azizah LM (2011). Keperawatan usia lanjut. Edisi ke 1. Yogyakarta: Graha Ilmu, pp: 1-2, 12, 25-27.

9. Yeni Y, Djannah SN, Solikhah (2010). Faktor-faktor yang berhubungan dengan kejadian hipertensi pada wanita usia subur di Puskesmas Umbulharjo I Yogyakarta tahun 2009. Jurnal Kesmas UAD, 4 (2)

10. Kalangi JA, Umboh A, Pateda V (2015). Hubungan faktor genetik dengan tekanan darah pada remaja. 
Jurnal e-Clinic (eCl), 3 (1): 66.

11. Setiadhi Y, Kawengian SES, Mayulu $N$ (2016). Analisis faktor yang berhubungan dengan kejadian hipertensi pada kehamilan di Kota Manado. Jurnal e-Biomedik (eBm), 4 (2): 2.

12. Kyu Ha S (2014). Dietary salt intake and hypertension. Electrolyte Blood Press, 12: 8-9. Review.

13. Larsen MK, Matchkov VV (2016). Hypertension and physical exercise: The role of oxidative stress. Aarhus, Aarhus University, pp: 19, 25-26. Review.

14. Mori Y, Tobina T, Shirasaya K, Kiyonaga A, Shindo M, Tanaka H (2011). Long-term effects of homebased bench-stepping exercise training on healthcare expenditure for elderly Japanese. J Epedemiol, 21 (5): 365.

15. Pestacello LS, MacDonald HV, Lamberti L, Johnson BT (2015). Exercise for hypertension: A prescription update integrating existing recommendations with emerging research. Curr Hypertens Rep, 17: 7 .

16. Bertschi AP, Burnier M (2004). Female sex hormones, salt, and blood pressure regulation. American Journal of Hypertension, 17 (10): 995.

17. Nurdiana (2008). Efek 17ß-Estradiol terhadap densitas reseptor adrenergik$\alpha$ ID dan kontraktilitas otot polos pembuluh darah tikus. Jurnal Kedokteran Brawijaya, 14 (2).

18. Houston MC (2011). The importance of potassium in managing hypertension. Curr Hypertens Rep, 13: 313-315.

19. Bazzano LA, Green T, Harrison TN, Reynolds K (2013). Dietary approaches to prevent hypertension. Curr Hypertens Rep, 15: 697-698.

20. Samadian F, Dalili N, Jamalian A (2016). Lifestyle modifications to prevent and control hypertension. Iranian Journal of Kidney Diseases, 10 (5): 244-246.

21. Djaelani EKP (2015). Pengaruh sari buah labu siam terhadap perubahan tekanan darah pada lansia penderita hipertensi di PSTW Budhi Luhur Kasongan Bantul Yogyakarta. Yogyakarta, Sekolah Tinggi Ilmu Kesehatan 'Aisyiyah. Naskah publikasi.

22. Puspito H (2014). Studi komparasi efektivitas pemberian madu, labu siam, labu siam dan madu terhadap tekanan darah penderita hipertensi primer di Dusun Pundung Nogotirto Gamping Sleman Yogyakarta. Yogyakarta, Sekolah Tinggi Ilmu Kesehatan 'Aisyiyah. Naskah publikasi. 